\title{
Changing panorama of mental illness, the role of environment - a key to prevention?
}

\author{
Letten F. Saugstad \\ Department of Anatomy, Institute for Basic Medical Sciences, University of Oslo
}

\begin{abstract}
The selective pruning of excitatory synapses - the final stage in brain development coincides with puberty. This makes pubertal age a determinant of excitability, the fundamental property of nervous tissue: the earlier puberty, the earlier is pruning arrested, the greater excitability. Age at puberty is only partly genetically determined. The 4 years lowering of mean pubertal age, a phenotypic response to improved living conditions (high protein diet) has been accompanied by a rise in manic-depressive psychosis and a decline in schizophrenia, mainly the nonparanoid more malignant forms. The maturational theory holds that early puberty is the necessary factor for developing manic-depressive psychosis; schizophrenia requires extremely late puberty. Their characteristic body-build supports this, as does the biological treatment, convulsant neuroleptics and mood-stabilizing anti-epileptics.

Kraepelin's endogenous psychoses, localized at the extremes of the maturational continuum, are part of normal variation in brain development. None of the CNS findings is outside normal variation. More pronounced findings are associated with exogenous factors (genetic and other disease, infection, pre-/perinatal morbidity).

Given manic-depressive illness and schizophrenia are part of human variation, concordance for multigenetic inheritance, shared loci and shared susceptibility but no single locus raising risk $>3$ are expected and observed. Findings of unique susceptibility loci for each disorder for regions of the genome where no linkage is reported for the other disorder accord with expectation.

The adversity of neuroleptics: attenuation of a CNS distinguished by reduced density of synapses, creates a need for alternatives. The decline in schizophrenia with lowering age at puberty offers a possibility of prevention. But pubertal age is declining further, excessive excitation renders the brain more unstable, further rise in manicdepressive illness, eating disorders and other disorders in early maturers, anxiety, panic attack, etc.

Our brain, probably because of its great size, is especially susceptible to dietary deficit in marine fat (DHA, Omega-3), its main component, which has to be provided by diet. Adding minor amounts markedly affect behaviour, and are used as adjunctive or sole anti-psychotic in disorders distinguished by excess/deficit in excitability, and other neurological disorders underlining the mismatch between the usual diet and our need for "brain-food".

Lithium is neuroprotective, population studies have demonstrated statistically significant reduced admission for psychosis, reduced violence, homicide etc. with higher levels of lithium in drinking water than with low levels (Dawson, 1991; Dawson et al, 1970, 1972). Substance abuse, a confounding factor in mental illness, might be reduced with lithium. With these important environmental factors - lithium and marine fat, we have the means to reduce psychopathology - improve well-being. We better start implementation.
\end{abstract}

\section{INTRODUCTION. THE INSUFFICIENCY OF Mendelian Genetics}

The scientific problems psychiatry poses are more exciting and interesting than in any other branch of medicine.

Several generations of psychiatrists have tried in vain to explain the neurobiological basis in mental disorders like schizophrenia and manic-depressive psychosis. Great advances have been made in neuroscience in the last decades with new techniques in molecular genetics focusing on sequencing and mapping the human genome. Let us examine the newly emerging field of psychiatric genetics how it contributes to solving the genetic puzzle in psychiatry, relating the two mental disorders to the human evolu- tion underlining the role of environmental factors and the normal variation especially in brain development.

Several research groups have collected large cohorts of affected families and screened the entire genome searching for chromosome segments which are linked to a psychiatric disorder. No finding has consistently reached the conventionally accepted statistical level for linkage for schizophrenia, yet several have emerged below this level covering more than two thirds of the genome (De Lisi \& Crow, 1999). Linkage studies of families with manic-depressive illness have also defined susceptibility loci for multiple regions of the genome, and many overlap with inherited vulnerability for schizophrenia (Berrettini, 2000). A single locus that increases risk for $>3$ has neither been reported in this disorder. The findings of concordance for 
multigenetic inheritance for schizophrenia and manicdepressive illness imply that shared loci are required for the full expression of the phenotype and shared susceptibility characterizes Kraepelin's endogenous psychoses.

The dichotomy seems less distinct, but for each disorder unique susceptibility loci have been verified for regions of the genome where no linkage has been reported for the other disorder. There appears to be greater likelihood of replicating findings of genes that are common in both disorders than of replicating those that are unique (Meltzer, 2000).

The plethora of confirmed linkage regions is overwhelming, but genetically homogeneous populations such as the isolated region in Northern Sweden with one of the highest known prevalence rates of schizophrenia have not provided more definite answers. The population has in fact descended from three Finnish families who settled in the region in the $18^{\text {th }}$ century (Saugstad, 1990). With diminishing hopes that Mendelian genetics will solve the genetic puzzle, we would have expected a discussion of multifactorial inheritance and a search for environmental factors. This has not happened. Nor has a difference in the selection of patients been discussed, a varying proportion of comorbidity (substance abuse), uncertainty as regards the diagnosis. Psychiatrists react to the shared susceptibility by considering the dichotomy as no longer valid. We see a revival of the concept of a Unitary Psychosis: a Psychosis Gene (Crow, 1990) concept of a continuum of psychosis. A concept which prevailed following Bayle's description of General Paralysis in 1822, where he demonstrated the many specific disease entities were just phases of development of the disease Syphilis. The unitary concept was abandoned following the introduction of Kraepelin's nosology.

\section{The Psychosis Gene - The Discontinu- ITY ARgument - Human UNIQUENESS}

How insufficiency of Mendelian genetics can lead to a suggestion that Kraepelin's psychoses are single gene disorders is difficult to understand. We are reminded of the discontinuity argument of language - human uniqueness (Crow, 2000). There is the hypothesis that complex language was instrumental in modern human origins (Schepartz, 1995). Specifically, there are no data suggesting any major qualitative changes in language abilities corresponding with the 200,000$100,000 \mathrm{BP}$ dates for modern Homo sapiens origins proposed by single origin models. Language rests on functions usually attributed to the left hemisphere, but increasingly frequent functions solely attributable to the left hemisphere are found to involve both hemispheres - the prefrontal-frontal regions as evidenced in brain imaging during silent speech (Ryding et al, 1995): according to Liberman (1983) functions initially attributed to the left may involve the right hemisphere, what is left of pure left function is the vocal articulation. Further we have evidence that cerebral lateralisation is not uniquely human (Bianki, 1988; Nottebohm, 1971; Kuhl, 1990; Denenberg, 1981). There is a frequent opinion of a gradual involvement of speech not a punctuated one, underlining that human speech is neither unique. What is uniquely human is the vast expansion of the neocortex. The prefrontalfrontal and parietal regions are considerably greater than in nonhuman primates. Our brain is about three times greater than expected from non-human primates. There are several theories for the expansion of the human brain: tool making is no argument, for it evolved after the brain had increased in size. A change in social life from competition to coordination and communication seem unlikely factors, as does genetic constraint as counterarguments to encephalisation. But brain size may vary considerably within species and eating habits might be a clue to larger brains (Eisenberg \& Wilson, 1978; Barton et al, 1995).

Our brain similar to other animals is rich $(60 \%)$ in polyunsaturated fatty acids (PUFA - marine fat), which have to be provided by diet. Given the excessive expansion of our brain, it might be especially susceptible to dietary deficit in marine fat (Saugstad, 1997, 1998). Let us search for environmental factors to verify how multifactorial inheritance explains shared loci and susceptibility in the two disorders if they are part of human variation in development.

\section{ENVIronmental FaCtors ANd MUlti- FACTORIAL INHERITANCE}

Allowing a wide scope for environmental influence multifactorial inheritance forms the basis for the finer adaptation of living organisms to their environment. It is generally accepted that continuous variables: height, age at puberty (rate of maturation) are multifactorially inherited. The importance of environment in relation to adult height and pubertal age is clear when we consider the $13 \mathrm{~cm}$ increase in mean adult height and four years decline in pubertal age in the last 100 years, a phenotypic response to improved living conditions (high protein diet) in Western Industrialized countries (Saugstad, 1989c, d, 1994a).

During the last decades it has become clear that the brain undergoes a series of developmental processes including expansion, reorganisation and regressive event. Further, as association has been established between onset of puberty and the final stage in brain development $-3^{\text {rd }}$ regressive event with selective pruning of some $40 \%$ of excitatory synapses. Similarly to endocrine irregularity at the extremes of the maturational rate continuum, we imagine greater risk of CNS irregularity at the extremes: very early and extremely late puberty. There is also a relation between age at puberty and body-build: early maturers tend to have a pyknic (broad) body type, and late maturer a linear leptosomic physique. This difference in stature and weight persists throughout life (Marshall \& Tanner, 
1986). The older psychiatric literature posited a relation between body-build and mental illness. The great majority of the population is of mixed body type (Kretschmer, 1921), pyknic body-build predominated $(90 \%)$ in manic-depressives, leptosomic, dysplastic body type characterized schizophrenics $(80 \%)$. This supports that schizophrenics are late maturers, manicdepressives early maturers and Kraepelin's dichotomy. He wanted to construct a consistent nosology to clarify classification. If the disorders occur at the extreme of variation in rate of maturation as part of human growth and maturation, this view would be supported if environmental change affecting pubertal age affects their incidence in a contrasting manner: schizophrenia declines with lowering of pubertal age, manicdepressive illness rises due to a rise in early maturers. We expect schizophrenia to predominate and manicdepressive illness to be rare in poor living conditions where pubertal age is high.

The decline in mean pubertal age from just below 17 years to slightly above 12 years offers a unique opportunity to verify our hypothesis. We have a confounding factor, it is unknown if a high protein diet adversely affected dietary content of marine fat - brain function. A changing panorama of mental illness as expected according to our hypothesis, does not prove why shared loci and susceptibility characterize Kraepelin's psychoses. This requires that CNS findings are within normal variation in brain structure in both disorders. Any estimate of changes in incidence of the disorders requires the availability of adequate hospital facility, a diagnosis for each admission and persistency in classification.

\section{RISE IN MANIC-DEPRESSIVE ILLNESS, DECLINE IN SCHIZOPHRENIA?}

The Norwegian National Case Register of Serious Mental disorder goes back to 1916, a co-worker of the founder, the late $\varnothing$. Ødegård, I was in charge until it was closed down in 1990 . There was a more than $50 \%$ increase 1926-65 in first-admissions classified manicdepressive psychosis/reactive depressive psychosis (Other psychosis ICD-298.0). Most patients with the latter diagnosis were rediagnosed as manic-depressives on re-admission. The increase occurred mainly after 1955, a growing proportion was classified nonpsychotic depression (ICD-300.4) which increased from $<5 \%$ in the 1940 s to $>20 \%$ in the eighties (Saugstad \& Ødegård, 1980). Many were involuntary admitted, being considered psychotic. Low ascertainment $(<50 \%)$ characterizes manic-depressive illness, a rise in admission despite the introduction of antidepressives and a striking reduction in beds in hospitals, is accepted supportive of a rise in affective illness. Denmark also has a National Register, and affective disorder has always been frequent in incidence. But similarly to Norwegians, Danish psychiatrists prefer the use of Other Psychosis initially and postpone a diagnosis of manic-depressive until readmission. They experienced a clear rise in disease expectancy 1947-1979 (Schou \& Strømgren, 1979). The Lundby study, Southern Sweden similarly found that the probability of suffering a depression had increased significantly 1947-1972. Hagnell et al (1982) entitled their paper “Are we entering an age of melancholy?" In Finland, annual census investigations are performed dividing the hospital population in three categories (Schizophrenia, Other Psychosis, Non-psychotic). Affective disorder is extremely rare. No detailed information is available by diagnosis from Sweden since the sixties.

In contrast to affective illness, ascertainment for schizophrenia was around $80 \%$ in Norway before introduction of neuroleptics in the 1950s. It is uncertain and considerably lower today. Similarly to the case as regards affective disorder, Norwegian and Danish psychiatrists prefer to diagnose Other Psychosis (ICD298) initially and postpone a diagnosis of schizophrenia until readmission. A more than $50 \%$ decline in admission rates for schizophrenia at a time when the number of hospital beds was at a maximum and the effect of neuroleptics was negligible has been accepted, indicating a decreasing incidence in both countries (Saugstad, 1994c). There are several confounding factors including later de-institutionalisation policy, and substance abuse. But it is clear that the more severe forms of the non-paranoids have been more or less eliminated (Saugstad \& Ødegård, 1985). Previously they were the most common sub-group in the male sex, whereas non-paranoid and paranoid schizophrenia were equally common in females. We experience new subtypes: acute, latent (pseudoneurotic), pseudopsychopatic, schizoaffective, borderline. The category most used is unspecified schizophrenia (ICD-295.8 \& 295.9), an atypical clinical psychopathological picture which could reflect previous drug abuse (Saugstad, 1994a, b, c, 1999, 2000). It is noteworthy that Kretschmer (1921) considered the non-paranoid the extreme leptosomic, we might add the most extreme late maturer. The Kraepelinian subtypes are useful indications of severity and of maturational rate, but a change away from more malignant forms was not observed in Northern Sweden in the fifties. Catatonia predominated (Böök, 1953), similarly in neighbouring Finland. First in a nationwide study from 1999, do Suvisaari et al report a decline in the incidence of schizophrenia in Finnish Cohorts 1954-1965.

Conclusion: the lowering of pubertal age, reduction in extremely late maturers, have as expected been accompanied by a reduction - elimination of more malignant forms of schizophrenia - the non-paranoid, extremely late maturers with pronounced leptosomic body-build. An estimate of the rise in affective illness associated with a rising number of very early maturers is more complicated. Depression is the least stigmatising of mental disorders, and was in fact excluded from the first Norwegian Census on Insanity in 1835. The diagnosis is preferred by psychiatrists (were you 
ever depressed?). A significant rise in life-time risk of depression was found where it was sought (Denmark and Southern Sweden). In Norway the increase in admission so classified was remarkable 1926-1965, it has just continued thereafter. A majority of manicdepressives medicate themselves, underlying depression is probably a common cause of substance abuse (Saugstad, 2000).

The disappointing course and outcome in both mental disorders in comparison with expectation when anti-psychotic medication was introduced in the fifties, raise several questions. Are the disappointing results associated with prior CNS pathology, if so, how is it to be explained? Could our biological treatment be harmful and result in CNS pathology? Let us examine the biological treatment and its effect on the brain in both disorders. We are reminded that we can infer etiology from treatment. Secondly, is brain structure in the two disorders within normal variation but localized at the extremes of variation?

\section{Biological Treatment In SCHIZOPHRE- NIA AND AFFECTIVE ILLNESS SUPPORTS THEY ARE DEVIATION FROM THE NORM THE INTERMEDIATE OPTIMUM OF NORMAL VARIATION IN CEREBRAL EXCITABILITY}

Given manic-depressive illness is a disorder in early maturers with abridged pruning before an optimal number of excitatory synapses has been eliminated and schizophrenia a disorder where the pruning process has proceeded past the optimal, the main discrepancy between these signalling disorders in the brain is a difference in excitability the fundamental property of nervous tissue: the Excitation/Inhibition ratio. We are reminded of Pavlov (1927), his concept of the excitation/inhibition ratio as a unique individual characteristic which he imagined might have a Gaussian distribution. Kraepelin's endogenous psychoses distinguished by excessive and a deficit in excitability respectively, nicely demonstrate that this might be the case. We therefore expect biological treatment to affect cerebral excitability in a contrasting manner: raising excitability in schizophrenia and lowering it in manic-depressive illness which is exactly what characterizes the anti-psychotic medication in the disorders. Schizophrenia is treated with convulsants, and moodstabilizing anti-epileptics are the treatment of choice in manic-depressive illness. The biological treatment thus does not argue in favour of specific disease processes (Mendelian genetics), but supports deviation from the norm: the intermediate continuum of cerebral excitability which secures CNS activity within normal limits.

Biological treatment is expected to be effective clinically only if physiological effects are recorded and neuroleptics (typical and atypical) all induce bilateral high voltage EEG paroxysms of slow waves mixed with spike-waves and focal epileptogenic activity. An atypical neuroleptic Clozapine may release myoclonus, convulsive seizures in 3-5\% and kindling phenomena. A main advantage of atypical neuroleptics is a reduced induction of extrapyramidal symptoms (EPS), tardive dyskinesia (TD) and a supposed positive effect on deficit symptoms. We expect side-effects (TD; EPS) to reflect the predilection of site of action and a doseresponse relationship. Continuous neuroleptics treatment for decades will probably produce side-effects in $100 \%$ such as described by Quinn et al (1998). In view of the concern about CNS damage in epilepsy it is remarkable that the adversity of continuous epileptiform changes common to all neuroleptics have been totally forgotten. EEG is no longer recorded and the CNS consequences of continuous convulsant EEG activity: white matter gliosis, reduction in grey matter volume and neuronal density are not mentioned when neuroleptics are discussed. This contrasts with our fear of raising excitability which is so marked that all neuroleptics primarily affect inhibition and only indirectly excitation. The adversity of neuroleptics has also been documented in animals: in 4 month old rats, only 16 weeks' exposure was sufficient to give striatal lesions and oral dyskinesia (Andreassen et al, 1998). Similar findings in primates, following a 6 month exposure (Selemon et al, 1999) to typical and atypical neuroleptics, but oral dyskinesia was not mentioned. Neuroleptics cannot cure; a pruning process gone to far cannot be reversed. We need biological treatment which prevents relapses and has an acceptable ratio of efficacy to side-effects, and prevents the development of the disorder in the future. Biological treatment should only be used for a limited duration - the psychotic period, followed by systematic efforts to teach the patient to cope with the common auditory hallucinations which are most probably caused by the therapy.

\section{MANiC-DePRESSIVE ILLNESS: THE ADVER- SITY OF BIOLOGICAL TREATMENT}

In view of our long experience with anti-epileptics, we would not expect their application in manic-depressive illness, a disorder similarly distinguished by excessive excitability to pose problems. Although anti-epileptics are the treatment of choice in addition to lithium, the actual practice differs markedly. Neuroleptics are used regularly in mania (Laly, 1997) despite the repeated reports of adversity which ranges from produced neurotoxic symptoms (seizures, delirium, encephalopathy and grossly abnormal EEGs) (Spring, 1979) to cardiac and respiratory arrest (Menes et al, 1980). There is a trend towards lower doses of neuroleptics, but as Daly (1997) states: "in more severe cases, lithium alone is impractical and it may then be combined with neuroleptics which have a faster onset of action". EEG pathology has especially been recorded in "rapid cycling", a sub-group distinguished by quite unpredictable chaotic mood swings and a raised risk of suicide. It is observed with increasing frequency in a number of patients once they have received anti-depressants 
(tricyclics and MAO inhibitors, Kilzieh \& Akiskal, 1999; Chen et al, 1999). EEG studies in animals and man have revealed complex effects, some of which change with the dose: low doses tend to stimulation and arousal and can produce seizure activity (Wehr \& Goodwin, 1987). Thus the rise in rapid cycling could be attributable to anti-depressants and its stormier course to the continuous use of neuroleptics. Usually, a change to anti-epileptics first follows a failure of neuroleptics, despite they have been reported to be effective. Against this background of maltreatment: the use of convulsants in a disorder distinguished by excessive excitability, a deterioration in course and outcome comes as no surprise. A disorder where mostly personality returned to normal premorbid following the cessation of a psychotic episode has changed to a disorder where cognitive deficits persist between relapses. Usually no CNS pathology was recorded (Ashcroft, 1982) where the new imaging techniques reveal deviation (Daly, 1997). While the importance of duration of depression is predicting CNS changes is discussed, there is no mention of the probability of treatment effect (Sheline et al, 1999), which seems most likely apart from a greater accuracy. A confounding factor is that a majority "medicate themselves", which is important in view of the marked suicide risk in substance abuse and its significant rise in affective illness from 3 to 20 times the general population following anti-psychotic medication (Saugstad, 2000). Similarly, suicide risk in schizophrenia has increased: from about equal to nine times the general population underlining the adversity of neuroleptics (persistency of auditory hallucinations due to attenuation of a CNS already distinguished by a reduced density of synapses) apart from the role played by the deinstitutionalisation and liberalisation policy and substance abuse which similarly predominates in this disorder.

Let us investigate brain structure if it accords with the extremes of variation with no specific abnormality pathognomonic for the two disorders.

\section{Brain STRUCTURE IN MANIC-DEPRESSIVE ILLNESS AND SCHIZOPHRENIA IS AS EXPEC- TED AT THE EXTREMES OF THE MATURA- TIONAL RATE CONTINUUM WITH NO Specific Pathognomonic Abnormality}

The association between the final stage in brain development $-3^{\text {rd }}$ regressive event and onset of puberty, suggests similar continuous (dimensional) variation in brain development with an intermediate optimal maturational continuum and at the extremes irregularity. The prepubertal regressive event is preceded by two retractive events: the first event takes place before birth and comprises the elimination of some $40 \%$ of the generated neurons, the second event occurs in infancy when the initial diffuse profections and abundance of inter-/intra-hemispheric connections are transformed to discrete specific projections by axonal and dendritic retraction (Saugstad, 1998, 1999). The discrepancy in structure and function in early fast and late slow maturers increases with each event: from a discrepancy in the neural population at birth, to a difference in neural arborisation in infancy, and a striking discrepancy in synaptic density and excitability accompanies the final event. In early fast maturers where the retractive events are prematurely arrested, this leaves a number of intra-/interhemispheric connections not usually present in the adult, and a greater density of neurons which is not verifiable. Conversely, in late maturers the retractive events proceed past the optimal we expect an overall reduced connectivity inter-/intrahemispherically, reduced axonal/dendritic branching, shorter branches than optimum and in extreme cases reduced cell size. The effect on brain volume of elimination of approx. $40 \%$ of the generated axonal and dendritic arborization in only opposed by the concurrent myelination of the projecting systems and the continuous growth of the brain. In extreme cases we expect cerebral atrophy - reduced brain size - microcephaly. We have evidence of excessive pruning in schizophrenia such as a more pronounced reduction in cortical grey matter, sulcus widening and increased CSF. Various imaging techniques have been used and reduction of the prefrontal-frontotemporal volume has been observed. The findings vary greatly, they have in common that there invariably exists considerable overlap between the patients and the controls, so several investigators have had to rely on a comparison of means in order to observe differences (Nasrallah \& Weinberger, 1986). Late slow maturation, delayed milestones and development, poor premorbid function are expected and have been recorded (Wahbeck et al, 2001). The findings vary greatly, different criteria are used for selection. The varying degrees of suboptimality support schizophrenia as a continuous variation in maturational delay. To diagnose maturational rate at birth we may use brain asymmetry. This is because brain asymmetry originates early in life, and the human brain is laterally asymmetrical most markedly in posterior superior temporal region (Planum Temporale, PT). Leftward asymmetry predominates in from 54 to $70 \%$, PT symmetry in less than $30 \%$ and only in $11-18 \%$ reversed rightward PT (Kuhl, 1988; Saugstad, 1998, 1996). There is a similar distribution pattern of PT asymmetry and sidedness preference (56\% total right-sidedness comprising handedness, footedness, and ear and eye dominance), 30\% ambilaterals and $14 \%$ wholly left-sided. This suggests a common underlying factor, a left-hemisphere maturational gradient. PT leftward asymmetry and right-sidedness signify early maturation which thus may be diagnosed at birth (handedness). As expected the schizophrenics have an excess of PT symmetry/reversal as well as of lefthandedness and ambi-laterality (Saugstad, 1999). Kraepelin discussed "diminished mental efficiency" and included disturbance of cognition and perception. Differential cognitive abilities are found most consis- 
tently in the verbal and spatial domains, where the pattern of these capabilities suggests that they develop independently of one another. While spatial ability changes with pubertal age and has a maximum in late maturers, verbal ability is unaffected by maturational rate (Waber, 1976, 1977). Although the right hemisphere is ahead of the left, the right frontal lobe is the last to reach maturation. We have thus another measure of maturational rate. The ratio Performance/Verbal scores on the WAIS (Wechsler Adult Intelligence Scale), the later age at puberty the greater the ratio. A diagnosis of developmental dyslexia (DD) is usually based on the discrepancy score between actual reading achievement and what would be predicted from IQ tests. Early maturers (higher Verbal than Performance scores) in view of the evidence may be protected from $\mathrm{DD}$, while late maturers run a risk. However, the cognitive profile even at an early stage such as at admission to hospital does not reflect the "premorbid personality". Schizophrenia is deeply rooted in the personality. Nor can it be excluded that they have had episodes of psychotic breakdown without seeking medical advice (Saugstad, 1994a, b).

Similar to schizophrenia, DD is distinguished by a prevalence of left-handedness, ambilaterality, PT reversal and symmetry. The risk of schizophrenia in individuals with DD is according to Doody et al (1996) about three times that in the general population.

Suboptimality - late maturation, is more susceptible to adversity that early maturers at all stages of development. What do we know about neuroprotective factors of importance in human development?

\section{LITHIUM IS NEUROPROTECTIVE AT ALL LEVELS OF EXCITABILITY}

Usually the therapeutic effects of lithium are considered specific to affective disorder where lithium prophylaxis is considered the most promising way to reduce suicide risk, but little is known about its actual involvement in brain function. Let us consider what is known about lithium and its effect on our brain. Lithium is widely distributed throughout the Earth's crust, but it is only found in the vicinity of volcanoseismic activity where such geological upheavals do lead to highly mineralised water and soils. It has a wide range of effects which gradually have come to our knowledge (Clench et al, 1981). For our purpose its neurotrophic effect is of main interest. Lithium has a robust effect on the expression of bcl-2; it indeed exerts neurotrophic/neuroprotective events in the human brain in vivo (Moore et al, 2000, Nonaka and Chuang, 1998a, Chen et al, 1999). Bcl-2 is the acronym for the B-cell lymphoma/leukemia-2 gene, first discovered because of its involvement in B-cell malignancies. Bcl-2 protects the neurons from a variety of insults from cell death, growth factor deprivation, ionising radiation to oxidant stressors among others.

When lithium was given in therapeutic doses to patients with manic depressive illness but medication free and to healthy volunteers, $\mathrm{N}$-acetyl-aspartate (NAA), a putative marker of neuronal viability and function, significantly increased in all regions of the brain investigated with quantitative proton magnetic resonance spectroscopy (Moore et al, 2000). A neuroprotective effect of lithium as an explanation for its beneficial effect is especially discussed at a time when similar to the many convoluted hypotheses concerning the schizophrenic disorder, we now see a multitude of postulates to explain the disappointing clinical course and outcome in MDP as well as the deviating CNS findings on MRI, SPECT, PET etc. Most importantly, lithium reduces the CNS deviations in cell loss and atrophy (Manji et al, 2000). Lithium therapy even leads to neuropil increases and thus to increased grey matter volume. There is no mention that the structural deviations could be the results of our treatment (neuroleptics in mania, tricyclics and MAO inhibitors in depression). To date, we have no investigation of treatment naïve MDP with these radiological methods to demonstrate that cell loss and cerebral atrophy are part of MDI. Nor have we any series of MDP patients treated only with marine fat (Omega-3) which have been examined with the radiological techniques (Horrobin, 2002).

Given the beneficial effect of lithium - reversal of structural CNS abnormality, the tap water content of lithium might be of importance in mental illness. Dawson et al $(1970,1972,1991)$ have investigated the relation between the tapwater levels of lithium and Mental hospital admission (1978-87) for 27 Texan counties, 6 million inhabitants 1968, for psychosis, schizophrenia, neurosis, personality problems and homicide. A statistically significant relation was demonstrated between the drinking water content and the renal excretion of lithium in persons of 16 years of age. There was a statistically significant relation also between rates of mental hospital admission for these four categories and for homicide. The lower lithium levels the higher admission rates. They conclude: "depending upon the quantity of lithium ingested, absorbed by the body, utilized by tissue cells and finally excreted it would seem that the populace of any community should derive a prophylactic benefit with respect to the four major forms of mental illness and to homicidal aggression." Schrauzer and Shrestha (1991) found that the incidence rates of suicide, homicide, and rape were significantly higher in Texan counties with drinking water supplies containing little or no lithium than in counties with water lithium levels ranging from 70-170 $\mu \mathrm{g} / \mathrm{l}$. The difference remained statically significant after correction for population density.

Fish, seafood or Omega-3 dietary intakes are other factors in depression and suicide. We have Hirayama's (1990) study of 265,000 Japanese subjects followed for 17 years, where regular fish consumption was associated with a reduced risk of suicide. Tanskanen et al (2001) in a study from Finland of 3,000 randomly 
selected individuals observed that regular fish consumption was associated with a significantly reduced risk of depression and of suicidal ideation.

\section{Human Nature is UniQue in the Mis- MATCH BETWEEN THE COMMON DIET AND OUR NEED FOR "FOOD FOR THE BRAIN"}

Infants recovering from severe malnutrition remain severely mentally retarded despite somatic recovery, and less pronounced malnutrition is associated with learning and behaviour disorder (Cravioto and Arrieta, 1986). Sound nutrition is clearly of decisive importance for brain development, but what is sound nutrition?

There are different principles involved in body growth and brain growth. Whereas protein is relevant to body growth, the structural material of the brain is some $60 \%$ lipid (marine fat), which has to be provided by diet. Just as essential amino acids are needed for protein synthesis, so are essential fatty acids required for lipid synthesis during brain development. We are reminded that during pregnancy, some $70 \%$ of the total energy to the fetus goes to brain development (Saugstad, 1997, 1999). The dolphin, a marine mammal with a highly complex brain, obtains marine fat preformed from its food supply, whereas a human with a far greater and more complex brain, tends to favour a high protein diet. Human nature is unique in this mismatch between our great need for brain food (PUFA) and the diet commonly adopted. Nowhere is this neglect of the brain more pronounced than in maternal nutrition, where protein is the only major nutrient considered. This is important since the about $13 \mathrm{~cm}$ mean increase in height in Western societies in the last century has been attributed to a high protein diet, while we know nothing about concomitant brain change. A high protein diet has repeatedly been associated with adversity pre- and perinatally, an increase in very preterm delivery, a depressed birth weight and an increased neonatal death rate. It is reasonable to attribute these phenomena to a lack of, or a negligible amount of marine fat (Saugstad, 1997). A regular but minor amount of fish increases birth weight, prolongs gestation and reduces preterm birth (Olsen et al, 1992) even when initiated in third trimester of pregnancy.

What do we know about later effect on brain development of a diet deficient in marine fat (Omega-3)? Does it lead to losses in CNS function? This seems quite likely when we consider that conditions of protein malnutrition all are more or less lacking in marine fat. We may ask, could adding marine fat together with protein have prevented brain dysfunction? That a dietary deficiency in Omega-3 affects brain function is evident in rats fed a diet which was totally deficient in Omega-3 (Salem et al, 1999). Brain/retinal DHA were markedly depressed in the $2^{\text {nd }}$ and $3^{\text {rd }}$ generation of rats, while Omega-6 polyunsaturates (DPA) increased and lead to losses of performance accompanying the "reciprocal replacement" of DHA in olfactory discrimination task, vision and Morris Water Maze Task. "The functional deficits associated with low brain Omega-3 related to sensory function were considered due to losses in higher level functions related to information processing in the brain that are necessary for memory and learning." A totally deficient diet is rare, but an insufficient dietary amount of marine fat Omega-3 is probably the rule, considering the common Western diet.

\section{We got a Head Start by Eating Fish, We BetTer Continue}

What is unique in humans is the vast expansion of the neocortex - prefrontal, frontal and parietal cortices which is considerably greater than expected in relation to our body weight and compared with the chimpanzees. Given our striking discrepancy in phenotype despite a remarkable similarity in genotype (98.4\%) in humans and chimpanzees, this suggests an adaptation to a life in a totally different environment, which must have comprised nutrition favouring encephalisation, i.e. seafood. According to Tobias (2002), a leading paleontologist, it is an old proposal that mankind evolved some of its distinctive features in an aquatic environment. Some ancestors possibly enjoyed a diet of seafood and animal meat for some million years. This has led to our large brain, which like other brains largely consists of marine fat (PUFA). This would reasonably explain our large brain and need for dietary PUFA, but not why we have almost completely neglected our need for "brain food". Our knowledge is incomplete as regards optimal diet (profile of DHA, EPA, AA, Omega-3/Omega-6) to secure optimal brain growth, prevent - reduce neurological disorders ranging from manic-depressive psychosis and schizophrenia at the extremes of the maturational rate continuum to disorders in the intermediate optimum: epilepsy, multiple sclerosis among others.

Rising standard of living is a main factor in maturational rate (pubertal age) as demonstrated in the last century, with the marked decline in pubertal age and rise in disorders in early maturers, and decline in schizophrenia a disorder in late maturation. Not unlikely prevention of both psychotic disorders is possible with a sufficient dietary intake of "food for the brain", and similarly as regards neurological nonpsychotic disorders. This is because marine fat normalizes brain function at both extremes and in the intermediate optimal. Given the chronic neglect of brainfood, the classical question whether mental illness is increasing may be answered in the affirmative. The marked rise in affective disorder, particularly increase in violent behaviour, substance abuse, suicide, homicide, in Western societies concomitantly with a decline in age at puberty could reasonably be explained by a low intake of marine fat. Given that lithium reduces human suicidal, violent behaviour, lithiation of the 
communal water supplies as suggested (Schrauzer and Schresta, 1991) could provide a simple, safe means of reducing this behavioural adversity characteristic of our Western societies.

\section{Prevention of Mental Illness, Early TreatMent AND NEUROLEPTICS}

The emphasis upon early treatment is old in psychiatry. When mental hospitals came into existence optimism was high. It was often stated that good results were certain if the patient was admitted during the initial stage of the illness. The optimism gradually declined as chronic cases accumulated in the hospitals. A certain optimism came back with the revival of occupational therapy, but a true new optimism did first occur with the somatic shock therapies in the midthirties. We got statistical arguments showing the importance of early treatment, admission, and mean duration of illness declined markedly (Ødegård, 1954). But delayed admissions did not disappear, and is felt as a serious medical-social problem today.

With the underlying assumption that the diagnosis is schizophrenia psychosis treatment prior to psychosis onset is recommended and in operation in several places (McGlashan, 2001). Klosterkötter (1994) was interested in whether the presence of Basic Symptoms (mild, subjectively experienced deficiency) represented an increased risk of the disorder. In a 17 years follow-up of 648 patients attending a psychiatric policlinic 1970-88, in whom Basic Symptoms had been recorded, there remained 348 non-psychotic patients, of whom 96 were re-examined. A Schizoid Personality Disorder had been diagnosed in five patients; schizo- phrenia had developed in 30 of 96 patients. In view of the discrepant effect on cerebral excitability of neuroleptics and anti-depressives any introduction of biological treatment without a clear diagnosis is not advisable. The adversity of long-term treatment with both types of drugs has to be considered. The occurrence of spontaneous remission is another factor. A 19 year old Japanese female (Uehara et al, 2000) with catatonic stupor had spontaneously recovered from two episodes of "delusional-hallucinatory states" a year earlier. SPECT imaging at the time of recovery showed significant improvement of RCBF frontoparietally, especially in the left parietal area.

Prevention is simple if we accept multifactorial inheritance and the environmental factor marine fat, which normalizes CNS function at all levels of excitability. Serious side effects do not exist, on the contrary, all of us whether adults or children profit from an addition of Omega-3 to diet. A speeding-up of development in slow maturers with increased risk of schizophrenia (Isohanni et al, 2001) is neither problematic. We have means of prevention without the adversity of anti-psychotics; we better start with marine fat.

\section{ACKNOWLEDGEMENT}

I would like to express my gratitude to Dr. Pierre-Marie Lledo, Institut Pasteur, Paris for helpful discussion especially on the role of environmental factors in human brain development. I would also like to express my gratitude to Professor Phillip V. Tobias, School of Anatomical Sciences, University of Witwatersrand, Johannesburg, South Africa for discussing the multifaceted dependence of early humanity on water with me.

\section{REFERENCES}

Andreasen LC, Nasrallah HA, Dunn V, et al (1986), Structural abnormality in the frontal region in schizophrenia. A magnetic resonance study. Arch Gen Psychiatry 43: 136-44.

Ashcroft G (1982), Biochemistry and pathology of the affective psychoses. In: Wing JK, ed. Handbook of Psychiatry Vol. III: 106-66.

Barton RA, Purvis A, Harvey PH (1995), Evolutionary radiation of olfactory brain systems in primates, bats and insectivores. Philos Trans R Soc Lond Biol Sci 348: 381-92.

Berrettini WH (2000), Susceptibility loci for bipolar disorder overlap with inherited vulnerability to schizophrenia. Biol Psych 47: 245-51.

Bianki VL (1988), The right and left hemispheres in the animal brain. Gordon and Breach, New York.

Böök JA (1953), A genetic and neuropsychiatric investigtion of a north Swedish population. Acta Genet 4: 1-100.

Chen G, Hasant KA, Bebchuk JM, et al (1999), Regulation of signal transduction pathways and gene expression by mood stabilizers and anti-depressants. Psychosom Med 61: 599-617.

Clench J, Ferrell RE, Schull WJ, Barton SA (1981), Hematocrit and hemoglobin, ATP and DPG concentrations in Andean man: The interaction of altitude and trace metals. In: Brewer GJ, ed. The Red Cell, $5^{\text {th }}$ American Arbour Conference. New York: Alan A. Liss, 2-13.

Crow TJ (2000), Schizophrenia as the price that Homo Sapiens pays for language. A resolution of the central paradox in the origin of the species. Brain Res Rev 31: 118-29.

Crow TJ (1990), The continuum of psychosis and its genetic origins. Br J Psychiatry 156: 788-90.

Daly J (1997), Mania. Lancet 349: 1157-60. 
Dawson EB (1991), The relationship of tap water and physiological levels of lithium to mental hospital admission and homicide in Texas. In: Schrauzer GN, Klippel K-F, eds. Lithium in biology and medicine. Weinheim: $\mathrm{VCH}, 169-87$.

Dawson EB, et al (1970, 1972). See Schrauzer \& Shrestha (1991).

Denenberg VY (1981), Hemispheric laterality in animals and the effect of early experience. Behav Brain Sci 4: 149.

Doody GA, Muir WJ, Johnstone EC, Owens DGC (1996), A new and familial variant of schizophrenia? Schizophr Res 18: 170-1.

Eisenberg JF, Wilson DE (1978), Relative brain size and feeding strategies in the chiroptera evolution 32: 740-51.

Gravioto J, Arrieta R (1986), Nutrition, mental development, learning and human growth. In: Falkner P, Tanner T, eds. Vol. III, pp. 501-35. New York.

Hirayama T (1990), Life-style and mortality. A large census-based cohort study in Japan. Basel: Karger.

Horrobin DF (2002), Cardiovascular disease, affective disorders and impaired fatty acid and phsopholipid metabolism. In: Chen E, Ares D, Kahora C, Duritz M, eds. Vascular disease and Affective Disorder. London, 9: 120.

Isohanni M, Jones PB, Moilanen K, et al (2001), Early developmental milestones in adult schizophrenia and other psychoses. A 31-year follow-up of Northern Finland 1966 Birth Cohort. Schizophr Res 52: 1-19.

Kilzien N, Akiskal HS (1998), Rapid cycling bipolar disorder. Overview of research. Psychiatr Clin North Am 22: 585-607.

Klosterkötter J (1994), Warning signs and symptoms in schizophrenia in psychiatry and mental health - the legacy of Ørnulv Ødegård. Saugstad LF, ed., p. 113-36.

Kretschmer E (1921), Körperbau und Character. Heidelberg.

Kuhl PK (1988), On handedness in primates and human infants. Behav Brain Sci 11: 727-9.

Lehtinen V, Joukamaa M, Lahtela K, et al (1990), Prevalence of mental disorders among adults in Finland: basic results from the Mini Finland Health Survey. Acta Psychiatr Scand 81: 418-25.

Lieberman JA (1983), Schizophrenia, comments on genes, development, risk factors, phenotype and course. Biol Psychiatry 46: 869-70.

Manji HK, Moore GJ, Chen G (2000), Clinical and preclinical evidence for the neurotrophic effects of mood stabilizers: implications for the pathophysiology and treatment of manic-depressive illness. Biol Psychiatry 48: 740-54.

Marshall WA, Tanner JM (1986), Puberty. In: Falkner F, Tanner JM, eds. Human Growth, Vol. II. New York: Plenum Press, 171-209.

McGlashan TH (2001), Psychosis treatment prior to psychosis onset: ethical issues. Schizophr Res 51: 47-54.

Meltzer HY (2000), Genetics and etiology of schizophrenia and bipolar disorder. Biol Psychiatry 47: 171-3.

Menes Churrar P, Hoaken PC (1980), Untoward effect following combined neuroleptics-lithium therapy. Cardiac arrhytmias and seizure. Can J Psychiatry 25: 573-6.

Moore GJ, Bebchuk JM, Khondakar H, et al (2000), Lithium increases N-acetyl-aspartate in the human brain. In vivo evidence in support of bcl-2's neurotrophic effects? Biol Psychiatry 48: 1-8.

Nasrallah HA, Weinberger DR (1986), The neurology of schizophrenia. Handbook of Schizophrenia, Vol. 1.

Nonaka S, Chuang DM (1998), Neuroprotective effects of chronic lithium of focal cerebral ischemia in rats. Neuroreport 9: 2081-4.

Nottebohm F (1972), Neural lateralisation of vocal control in a passerine bird: subsong calls and a theory of vocal learning. J Exp Zool 1719: 25-50.

Olsen SF, Soerensen JD, Secher, et al (1992), Randomised controlled trial of effect of fish-oil supplementation on pregnancy duration. Lancet 339: 1003-7.

Pavlov TP (1927), Conditioned reflexes. London: Oxford University Press.

Quinn J, Meagher D, Murphy P, et al (1998), Vulnerability to involuntary movements over a lifetime of severe schizophrenia approaches 100\% in association with frontal lobe dysfunction. Schizophr Res 29: 178-9.

Ryding ED, Brådvik B, Invar DH (1996), Silent speech activates prefrontal regions asymmetrically as well as a speech-related area in the dominant hemisphere. Brain Lang 52: 435-51.

Salem N, Greiner R, Moriguchi T, et al (1999), A diet low in N-3 fatty acids lead to low brain DHA and also lead to losses of nervous system function. Workshop Sept. 1999 on the essentiality of a dietary reference intakes (DRIS) for Omega-6 and Omega-3 fatty acids. National Institute of Health, Bethesda MD, USA.

Saugstad LF (1989a), Social class, marriage, and fertility in schizophrenia. Schizophr Bull 15: 9-43.

Saugstad LF (1989b), Age at puberty and mental illness. Towards a neurodevelopmental etiology of Kraepelin's endogenous psychoses. Br J Psychiatry 155: 536-544.

Saugstad LF (1989c), Mental illness and cognition in relation to age at puberty: a hypothesis. Clin Genet 36: 15667.

Saugstad LF (1989d), Human growth and maturation. Have we passed the optimal? Scand Pop Stud 9: 189-217. 
Saugstad LF (1990), Social class, marriage, and fertility in schizophrenia. The author replies. Schizophr Bull 16: 175-8.

Saugstad LF (1994), In Ødegård's Footsteps and Further: The maturational theory of brain development and Kraepelin's multifactorially inherited psychoses. In: Psychiatry and Mental Health - the Legacy of Ørnulv Ødegård. Stockholm: Författares Bokmaskin, 167-240.

Saugstad LF (1994a), The maturational theory of brain development and cerebral excitability in the multifactorially inherited manic-depressive psychosis and schizophrenia. Int J Psychophysiol 18: 189-203.

Saugstad LF (1994b), Deviation in cerebral excitabily. Possible clinical implications. Int J Psychophysiol 18: 20512.

Saugstad LF (1998), Cerebral lateralisation and rate of maturation. Int J Psychophysiol 28: 37-62.

Saugstad LF (1999), A lack of cerebral lateralisation in schizophrenia is within the normal variation in brain maturation but indicates late, slow maturation. Schizophr Res 39: 83-196.

Saugstad LF (2000a), Editorial: Suicide and resilience. The role of mental illness, psychotropic medication and abuse. Int Med J 7: 169-80.

Saugstad LF (2000b), On the relation between nature and nurture or the relevance of human growth and maturation in psychiatry. Acta Neurol Scand (Suppl 102): 12-4.

Saugstad LF (2002a), Human nature is unique in the mismatch between the great need for brainfood and the common diet. Nutr Health 16: 38-42.

Saugstad LF (2002b), Our neglect of the normal variation is linked to a reluctance to accept multifactorial inheritance and the role of environment. Med Hypotheses, In press.

Saugstad LF (2002c), Introduction to "Marine Fat and Human Health". Symposium in honour of Elaine Morgan 4 Nov. 2000, Norwegian Academy of Science and Letters. Nutr Health Suppl. 16: 1-2.

Saugstad F, Ødegård Ø (1980), Ingen internasjonal tilnærming. Nord Psykiatr Tidsskr 34: 455-64.

Saugstad LF, Ødegård Ø (1985), Recent rise in supposedly stress dependent causes of death in psychiatric hospitals. Acta Psychiatr Scand 71: 402-9.

Schepartz LA (1993), Language and modern human origins. Yearbook Phys Anthropol 36: 91-126.

Schrauzer N, Shrestha KP (1991), Lithium in drinking water and the incidence of crimes, suicides, and arrests related to drug additions. In: Schrauzer GN, Klippel K-F, eds. Lithium in biology and medicine. Weinheim: VCH, 190-203.

Selemon LD, Goldman-Rakic P (1999), The reduced neuropil hypothesis a circuit-based model of schizophrenia. Biol Psychiatry 45: 17-25.

Sheline YI, Sanghavi M, Minium MA, et al (1999), Depression duration but not age predicts hippocampal volume loss. J Neurosci 15: 5034-43.

Simopoulos AP (1999), Evolutionary aspects of Omega-3 fatty acids in the food supply. Prostaglandins Leukot Essent Fatty Acids 60: 421-9.

Suvisaari JM, Tanskanen AJ, Lönnqvist JK (1999), Decline in the incidence of schizophrenia in Finnish cohorts born from 1954 to 1965. Arch Gen Psychiatry 56: 733-40.

Tanskanen A, Hibbeln JR, Hintikka J, et al (2001), Fish consumption, depression and suicidality in a general population. Arch Gen Psychiatry 59: 512-3.

Tobias P (2002), Some aspects of the multifaceted dependence of early humanity on water. Nutr Health 16: 13-8.

Uehara T, Kawamurra T, Odano T, et al (2000), Recovery from catatonic stupor and change in cerebral perfusion. Int Med J 7: 197-9.

Waber DP (1976), Sex differences in cognition, a function of maturational rate? Science 192: 572-4.

Waber DP (1977), Sex differences in mental ability, hemispheric lateralisation. Dev Psychol 13: 29-38.

Wahlbeck K, Forsen T, Osmond C, et al (2001), Association of schizophrenia with low maternal body mass index. Small size at birth, and thinness during childhood. Arch Gen Psychiatry 58: 48-52.

Wehr TA, Goodwin FK (1987), Can anti-depressants cause mania and worsen the course of affective illness? Am $J$ Psychiatry 144: 140-51.

Ødegård Ø (1954), La genetique dans la psychiatrie. Proc. of the First World Congress, Paris, Vol. 6: 84-90, 115118. 